\title{
Developing clinical ethics committees
}

\author{
John Saunders
}

John Saunders MA

MD FRCP,

Consultant

Physician, Nevill

Hall Hospital,

Abergavenny;

Honorary

Professor, Centre

for Philosophy and

Health Care,

University of Wales,

Swansea

Clin Med

2004;4:232-4

KEY WORDS: clinical ethics, clinical governance, ethicist, ethics consultation, ethics forum, Ethox, Nuffield Trust

Autumn 2003 saw the launch of a clinical ethics network website (www.ethics-network.org.uk): another step in the development of bodies concerned with ethics applied to the practice of medicine. A very good site it is too, with links to relevant national policies, issues, clinical ethics committee contacts and so on. It coincided with a plea for clinical ethicists in the broadsheet press. ${ }^{1}$ Has clinical ethics finally come of age?

\section{Development of clinical ethics review bodies}

Clinical ethics as an organised activity in healthcare institutions has developed more slowly than its

\section{Key Points}

Clinical ethics committees were introduced over 30 years ago in the USA

Their responsibilities remain varied and their value uncertain

In the UK, development of clinical ethics committees has been slower

Although access to ethical opinion is important both for policy development and patient management, the clinical ethics committee may not be the best option

A forum to encourage education and discussion of ethical issues could be valuable

Further consideration of the roles of clinical ethics committees is required, especially in the context of clinical governance research ethics counterpart. Healthcare ethics committees formally began with the adoption of committees for the discussion of morals in medicine at American Catholic hospitals in the 1960s. ${ }^{2}$ Subsequently, the kidney-dialysis selection committees, abortion review committees and infant care review committees developed in various States over the next twenty years. Consultation on ethics was encouraged by the courts ${ }^{3}$ and endorsed by a major President's commission. ${ }^{4}$ By 1987, 60\% of American hospitals had either a formal ethics consultation service or a clinical ethics committee (CEC); in Maryland, this figure was $87 \%$, and all hospitals there had CECs by 1989. In 1992, the Joint Commission on the Accreditation of Healthcare Organisations passed a mandate that all its approved hospitals must put in place a means for addressing ethical concerns. The American Society for Bioethics and Humanities produced Core competencies for health care ethics consultation in $1998,{ }^{5}$ and set out the nature, goals and competencies of healthcare ethics consultation in $2000 .^{6}$ Consultation on ethical issues in medicine varies in its process in US hospitals - with ethics consultants (professional 'ethicists'), ethics forums or clinical ethics committees - but a formal structure of some kind is now universal. Some have sweeping powers.

In the UK, the professional clinical ethicist is rarely used. This may be partly because of continuing scepticism about the need for a formal service of any sort, and partly because such an individual would need to be overtly funded. Instead, the 1990s saw the development of CECs in centres such as Leeds, ${ }^{7}$ Northwick Park, ${ }^{8}$ Great Ormond Street and the Oxford Radcliffe NHS Trust. The independent King's Fund stipulated that mechanisms for the consideration of ethical issues must exist as 'essential practice' in its 1994 Organisational Audit programme, ${ }^{9}$ and described this mechanism as a 'forum' in its 1997 revision. ${ }^{10}$ It emphasised the adoption of a multidisciplinary approach to the consideration of ethical issues and the need to help both staff and families deal with dilemmas. But it fell short of recommending that the clinical ethics committee was the best or recommended mechanism for delivering such considerations.

The Centre for Ethics and Communication in Healthcare Practice in Oxford (Ethox) has played a leading role and currently organises an annual con- 
ference, training meetings and a regular newsletter. Ethox played the key part in the Nuffield Trust's extensive report on clinical ethics support in the UK, ${ }^{11}$ launched in 2001 with a supplement to the Journal of Medical Ethics dedicated to CECs. ${ }^{12}$ In other parts of Europe, developments have also been patchy but a Medline search reveals reports of CECs in most countries, both in Western and Eastern Europe.

\section{The current situation}

The Nuffield report remains the single most useful guide to the current situation, even if more CECs have undoubtedly been initiated since its publication. The survey that informed the report obtained replies from $99.8 \%$ of NHS trusts. Although $86 \%$ reported some form of ethics support, this was often informal and included recourse to clinical directors, other clinical colleagues, chaplains, research ethics committee chairmen and so on. At the time only 20 trusts (4.4\%) had CECs, although the figure is now probably nearer 70-80. The survey revealed strongly divergent views. On the one hand were supportive comments such as:

'I feel strongly that there are circumstances which could be better handled if we had access to individuals or processes which support ethically based decision making.'

'Sadly lacking. We devote much time to RECs [research ethics committees] but do not support clinicians with a "service" ethics committee. Often the question becomes a legal one when in truth it is not.'

By contrast, there were others who expressed a much more sceptical viewpoint:

'We don't need more committees. This can be dealt with by clinicians in the relevant clinical team, through NICE, Royal Colleges, other national guidelines and clinical governance structures.'

'I am somewhat alarmed at the growth of quasi formal/regulatory committees.'

This debate is not a new one. ${ }^{13}$ At least part of the concerns about CECs stems from their role. Even in the USA, there is enormous variation about what they are actually concerned with and how they are made up. ${ }^{14}$ The following statement of objectives, from a CEC in England, is a fairly typical example:

- To provide a high level of structured debate

- To encourage staff to bring dilemmas forward

- To provide a forum to review policies

- To advise on the implications of national guidelines

- To encourage educational opportunities

- To publicise the work.

A critic might comment that any management or advisory body might have the first of these objectives and that, if the CEC were really useful, the last would hardly be necessary. Reviewing (or developing) policies may be an invaluable task, but equally the necessary expertise may be better located in departmental bodies. The new website, for example, reveals that $54 \%$ of CECs contribute to trust policies and $20 \%$ frequently interpret national guidelines. Such functions may be valuable but it would be interesting to know if they are necessarily ethical. Eighteen CECs have concerned themselves with withdrawing and withholding therapy, 12 with 'do not attempt resuscitation' orders, and 11 with living wills/advance directives. In each of these cases, authoritative guidance is available from national bodies (in fact, mainly the British Medical Association). It is unlikely that any CEC could or indeed would wish to amend guidance that has resulted from an exhaustive consultation and commands a fair consensus. One presumes that the CEC can only concern itself with local application: how it is documented in our trust, who is responsible for auditing the policy etc. These matters are primarily empirical, not ethical. To that degree they may not require an ethics committee, although they may need some part of the trust's governance structure.

\section{What should be the role of CECs?}

Committees may not be the best way to respond to dilemmas arising in individual patients when acute problems arise. Perhaps the analysis of the acute clinical dilemma is best left to the professional ethicist, an ethics consultation team of three or four members or to an alternative structure. Inevitably a larger body is cumbersome (the largest CEC has 24 members) and lay involvement raises genuine issues of confidentiality that are quite different from the work of research ethics committees. Perhaps a forum to promote ethics in medicine, both in continuing education and practice should be the main role. A further role has also been described - that of the Greek chorus. ${ }^{13}$ The CEC does not act, but instead:

the chorus offers advice and history and support for the protagonist...establishes a moral resonance for the hero's fate. Its virtue is its presence and its sympathy and its clear meditation on his or her predicament in a social and historical context... Beyond the tragic ending, we imagine, the chorus will store up the memory of the struggle just ended, and this will in turn be the stuff of moral reflection on some future occasion. ${ }^{13}$

As Gillon reflects, this view is unlikely to appeal to toughminded seekers of quick decisions. What evidence is there that CECs serve a useful function? At least one randomised controlled trial has attempted to measure this in the intensive care setting. ${ }^{14}$ It was concluded that ethics consultations were useful in resolving conflicts that may have inappropriately prolonged non-beneficial or unwanted treatments in the intensive care unit. The same paper lists a number of less ambitious studies, all in the USA.

CECs are here to stay, but their role, responsibilities and composition remain to be determined. Even in the USA this is not clear. ${ }^{15}$ Since ethics concerns what we do (everything we do), there is a potential for a group of like-minded enthusiasts to pronounce on an enormous range of areas in which they have no special expertise. The competencies needed to serve on such a committee remain undefined; the role of the lay member, in contrast to those in research ethics committees, is not clear, especially if individual case problems are referred; nor is the 
position of CECs in clinical governance and the quality agenda agreed. There is a critical distinction between CECs offering an analysis of a dilemma to prescribing a solution, and concern that this boundary could easily be fudged. Yet for some, CECs may be seen as a luxury unless they are able to solve problems. This may be the reason that so few CECs in the UK have allocated funding. At present, although the need for access to ethical advice will be agreed, there will be cost implications and these will have to be considered against other priorities. ${ }^{16}$ In commenting on the New Zealand cervical cancer scandal, it was observed that external controls are blunt instruments in particular cases and that neglect of 'internal morality' is widespread. ${ }^{17}$ Nevertheless, the need for another regulatory or advisory body is controversial. CECs are open to the accusation that they are talking shops for people who like that sort of thing. The Nuffield report shows where we are in the UK, but there is a need for a major professional body, such as the Royal College of Physicians, to examine where we should be going.

\section{References}

1 Sokol DK. To live and let die. The Guardian, 11 September 2003.

2 McGee G, Spanogle JP, Caplan AL, Penny D, Asch DA. Successes and failures of hospital ethics committees: a national survey of ethics committee chairs. Camb Q Healthc Ethics 2002;11:87-93.

3 Cranford RE, Doudera AE. The emergence of institutional ethics committees. In: Cranford RE, Doudera AD (eds), Institutional ethics committees and health care decision making. Ann Arbor, MI: Health Administration Press, 1984:5-21.

4 President's Commission for the Study of Ethical Problems in Medicine and Biomedical and Behavioral Research. Decisions to forgo life-sustaining treatment. A report on the ethical, medical, and legal issues in treatment decision. Washington DC: GPO, 1983:155-70.
5 Society for Health and Human Values and Society for Bioethics Consultation. Core competencies for health care ethics consultation: the report of the American Society for Bioethics and Humanities. Glenview, IL: American Society for Bioethics Consultation, 1998.

6 Aulisio, MP, Arnold RM, Younger SJ. Health care ethics consultation: nature, goals and competencies. A position paper. Ann Intern Med 2000;133:55-7.

7 Thornton JG, Lilford RJ. Clinical ethics committee. BMJ 1995; 311:667-9.

8 Meslin EM, Rayner C, Larcher V, Hope T, Savulescu J. Hospital ethics committees in the United Kingdom. HEC Forum 1996;8:301-15.

9 King's Fund Organisational Audit, Hospital Accreditation Programme. Vol 1: Organisational standards and criteria. London: King's Fund, 1994:11.

10 King's Fund Organisational Audit. Accreditation UK. London: King's Fund, 1997:151.

11 Slowther A, Bunch C, Woolnough B, Hope T. Clinical ethics support in the UK: a review of the current position and likely development. London: The Nuffield Trust, 2001.

12 Clinical Ethics Committees Supplement. J Med Ethics 2001;27(suppl I).

13 Gillon R. Clinical ethics committees - pros and cons. J Med Ethics 1997; 23:203-4.

14 Schneiderman LJ, Gilmer T, Teetzel HD, Dugan DO et al. Effect of ethics consultations on nonbeneficial life-sustaining treatments in the intensive care setting JAMA 2003;290:1166-72.

15 McGee G, Caplan AL, Spanogle JP, Asch DA A national study of ethics committees. Am J Bioethics 2001;1:60-64.

16 Blackwood G. Ethics cost, whether you have them or not. BMJ 2001;323:936-7.

17 Paul C. Internal and external morality of medicine: lessons from New Zealand BMJ 2000; 320:499-503. 